\title{
Properties of $\mathrm{Bi}-\mathrm{Sr}-\mathrm{Ca}-\mathrm{Cu}-\mathrm{O}$ high $T_{c}$ superconductor
}

\author{
B SRINIVASULU NAIDU, B JAGANNADHA REDDY, \\ $Y$ PRABHAKARA REDDY and P JAYARAMA REDDY \\ Department of Physics, Sri Venkateswara University, Tirupati 517 502, India.
}

\begin{abstract}
The effect of sintering in air and annealing in oxygen flow at various temperatures and times on the superconducting transition of $\mathrm{Bi}_{2} \mathrm{Sr}_{2} \mathrm{Ca}_{1} \mathrm{Cu}_{2} \mathrm{O}_{8}$ ceramic was studied. Samples sintered at $1138 \mathrm{~K}$ for $24 \mathrm{~h}$ in air and slowly-cooled to room temperature are singlephase with the highest zero resistivity temperature of $88 \mathrm{~K}$. XRD pattern showed that the single-phase was characteristic of tetragonal structure with $a=0.5398 \mathrm{~nm}$ and $c=3.0620 \mathrm{~nm}$. Both a.c. susceptibility and resistivity measurements give similar values for the onset $(100 \mathrm{~K})$ of superconducting transition.
\end{abstract}

Keywords. High $T_{c}$ superconductor: annealing conditions; solid-state reaction; structure; resistivity: a.c. susceptibility.

\section{Introduction}

Superconductivity in $\mathrm{Bi}-\mathrm{Sr}-\mathrm{Ca}-\mathrm{Cu}-\mathrm{O}$ system was first reported by Maeda et al (1988), and depending on the composition of the system, the $T_{c}$ values go up to $110 \mathrm{~K}$ (Syono et al 1988; Takayama-Muromachi et al 1988). It is reported to have two superconducting phases; the low- $T_{c}$ phase $(85 \mathrm{~K})$ was identified as $\mathrm{Bi}_{2} \mathrm{Sr}_{2} \mathrm{Ca}_{1} \mathrm{Cu}_{2} \mathrm{O}_{8}$ (2212) by Hazen et al (1988a), while the high- $T_{c}$ phase is believed to have the composition $\mathrm{Bi}_{2} \mathrm{Sr}_{2} \mathrm{Ca}_{2} \mathrm{Cu}_{3} \mathrm{O}_{10}$ (2223) (Torrance et al 1988; Tallon et al 1988). The low- and high- $T_{c}$ phase samples have similar XRD and electron diffraction patterns but exhibit different temperature dependence of resistance. The high- $T_{c}$ phase is believed to have three closely-spaced $\mathrm{Cu}-\mathrm{O}$ planes instead of two as in the low- $T_{c}$ phase and the number of $\mathrm{Cu}-\mathrm{O}$ layers per unit length relates to the superconducting transition temperature (Hazen et al 1988b). Most of the studies reported suggest that it is easy to obtain a ceramic sample containing both low- $T_{c}(2212)$ and high- $T_{c}(2223)$ phases. The annealing temperature and time have been found to be crucial for the formation of high- $T_{c}$ samples (Liu Zhi Yi and Persson 1988) and to obtain sharp transitions (Perrin et al 1988). It is generally agreed that the oxide which forms most readily has the chemical composition $\mathrm{Bi}_{2} \mathrm{Sr}_{2} \mathrm{Ca}_{1} \mathrm{Cu}_{2} \mathrm{O}_{8}$ (2212) and a tetragonal structure with $a=0.54 \mathrm{~nm}$ and $c=3.08 \mathrm{~nm}$ and a $T_{c}$ of about $80 \mathrm{~K}$ (Almond et al 1988). The other phase with $T_{c}=110 \mathrm{~K}$, appears to be formed by a subsequent modification of the lower- $T_{c}$ phase by the inclusion of an additional copper oxide layer (Zandbergen et al 1988). However this conversion proved to be difficult and to date no single-phase sample with a $T_{c}$ of $110 \mathrm{~K}$ has been reported. Tallon et al (1988) reported an increase in the $T_{c}$ of 2212 from 80 to $91 \mathrm{~K}$ produced simply by quenching. In the present investigation an attempt has been made to study the effect of sintering in air and the effect of subsequent annealing in the oxygen flow at various temperatures and times on the superconducting behaviour of $\mathrm{Bi}_{2} \mathrm{Sr}_{2} \mathrm{Ca}_{1} \mathrm{Cu}_{2} \mathrm{O}_{8}$ single-phase ceramic. 


\section{Experimental}

$\mathrm{Bi}_{2} \mathrm{Sr}_{2} \mathrm{Ca}_{1} \mathrm{Cu}_{2} \mathrm{O}_{8}$ samples were prepared by the standard solid-state reaction technique. It has been reported (Tarascon et al 1988; Gadkari et al 1988) that the single-phase 2212 compound is not formed easily when the constituent oxides/carbonates are reacted in the stoichiometric ratio. The method employed to obtain a single-phase compound in the present study is as follows: $\mathrm{SrCO}_{3}$ and $\mathrm{CaCO}_{3}$ powders were mixed in the molar ratio $2: 1$, ball-milled to promote thorough mixing and calcined at $1273 \mathrm{~K}$ for $10 \mathrm{~h}$ and at $1673 \mathrm{~K}$ for $5 \mathrm{~h}$. Separate high temperature calcination of $\mathrm{SrCO}_{3}$ and $\mathrm{CaCO}_{3}$ mixtures at $1673 \mathrm{~K}$ resulted in complete decomposition. The reacted powder was cooled and ground well. To this material $\mathrm{Bi}_{2} \mathrm{O}_{3}$ and $\mathrm{CuO}$ powders were added in stoichiometric proportion, mixed, milled and heated at $1198 \mathrm{~K}$ in air for about $5 \mathrm{~min}$ till the mixture turned black. The reacted powder was slowly cooled and ground well. The mixture was calcined for $24 \mathrm{~h}$ in air at $1100 \mathrm{~K}$ and allowed to cool to room temperature in the furnace. The resulting material was subjected to second calcination for $12 \mathrm{~h}$ in air at $1135 \mathrm{~K}$ and allowed to cool to room temperature. The double-calcined powder was ground to a particle size of $100 \mu \mathrm{m}$ and pressed ( $4.5 \mathrm{kbar})$ to form pellets. The pellets were sintered in air at various temperatures ranging from $1073-1173 \mathrm{~K}$ for various periods $(10-30 \mathrm{~h}$ ), and slowly furnace-cooled to room temperature. The sintered samples were annealed in flowing oxygen atmosphere at various pressures $(0.01-100$ bars), temperatures $(873-1073 \mathrm{~K})$ and times $(4-24 \mathrm{~h})$. The sample resistance was measured using the four-probe technique in the temperature range $303-70 \mathrm{~K}$. The temperature dependence $(303-70 \mathrm{~K}$ ) of a.c. susceptibility was studied at $317 \mathrm{~Hz}$ and $0.05 \mathrm{Oe}$. The temperature of the sample was determined with a calibrated copper-constantan thermocouple. The crystal structure was determined by a Philips X-ray diffractometer at room temperature using nickel-filtered $\mathrm{CuK}_{x}$ radiation.

\section{Results and discussion}

The influence of sintering temperature and time on the superconducting characteristics of $\mathrm{Bi}_{2} \mathrm{Sr}_{2} \mathrm{Ca}_{1} \mathrm{Cu}_{2} \mathrm{O}_{8}$ is shown in figure 1. It is seen from figure 1(a) that to achieve the highest $T_{c}$, the samples must be sintered in air at $1138 \mathrm{~K}$ for $24 \mathrm{~h}$ and slowly cooled to room temperature. $T_{c}$ increases almost linearly with increasing sintering temperature up to $1138 \mathrm{~K}$ and then decreases. This decrease may be due to the fact that thermal treatment near or above the melting point degrades the superconducting properties as well as the structure. During slow furnace-cooling, the high- $T_{c}$ phase, even if present, decomposes while the low- $T_{c}$ phase is retained. Figure $1(\mathrm{~b})$ reveals that a sintering time of at least $22 \mathrm{~h}$ is necessary to have the highest $T_{c}$ in the samples. There is no systematic change in $T_{c}$ beyond $22 \mathrm{~h}$. Long-term sintering followed by slow cooling to room temperature appears to improve the bulk superconducting properties.

$\mathrm{Bi}_{2} \mathrm{Sr}_{2} \mathrm{Ca}_{1} \mathrm{Cu}_{2} \mathrm{O}_{8}$ samples sintered at $1138 \mathrm{~K}$ in air for $24 \mathrm{~h}$ and slowly cooled to room temperature showed a resistivity of the order of milliohm-cm. They are black in colour and are stable towards exposure to atmospheric conditions. To measure the resistance, voltage and current leads (platinum wires) were connected to the pellets with silver epoxy. Temperature dependence of resistivity of $\mathrm{Bi}_{2} \mathrm{Sr}_{2} \mathrm{Ca}_{1} \mathrm{Cu}_{2} \mathrm{O}_{8}$ is shown 


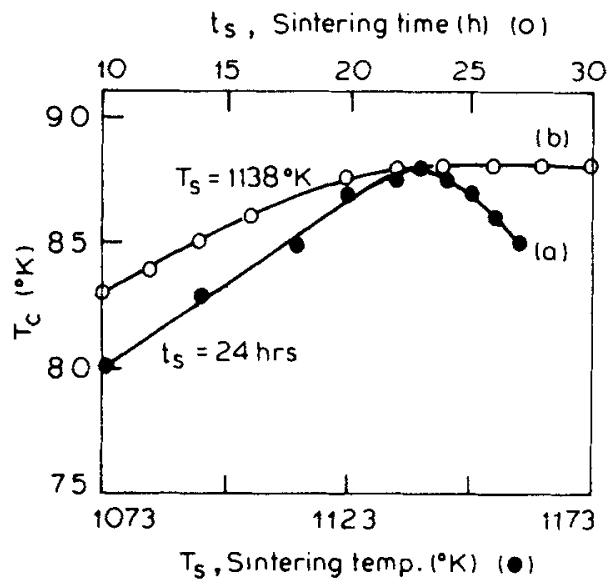

Figure 1. Superconducting characteristics of $\mathrm{Bi}_{2} \mathrm{Sr}_{2} \mathrm{Ca}_{1} \mathrm{Cu}_{2} \mathrm{O}_{8}$ as a function of (a) sintering temperature and (b) sintering time.

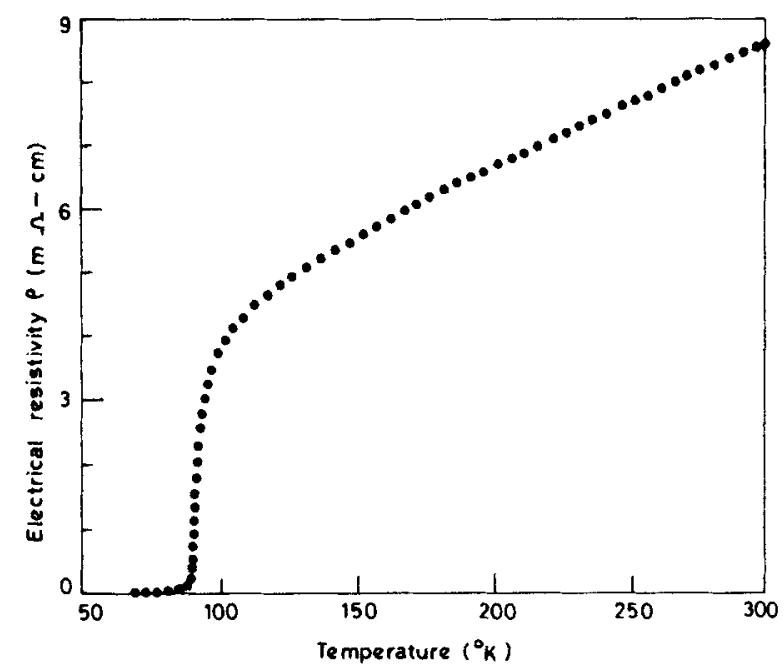

Figure 2. Temperature dependence of electrical resistivity of $\mathrm{Bi}_{2} \mathrm{Sr}_{2} \mathrm{Ca}_{1} \mathrm{Cu}_{2} \mathrm{O}_{8}$ sintered at $1138 \mathrm{~K}$ for $24 \mathrm{~h}$.

in figure 2. The behaviour is metallic between 303 and $100 \mathrm{~K}$ and the resistivity drops at about $100 \mathrm{~K}$ becoming zero at $88 \mathrm{~K}$. The transition width and temperature dependence of resistivity above $T_{c}$ strongly depend on the sintering temperature and time. The sharp transition observed implies that the samples are homogeneous and single-phase and that the major phase must be superconducting.

The temperature dependence of a.c. susceptibility was determined by monitoring the mutual inductance of two coils close to the sample. The a.c. susceptibility measured on a sample is shown in figure 3 . At room temperature the specimen is paramagnetic and on cooling, changes to diamagnetic state at $100 \mathrm{~K}$. A large change in inductance signal suggests the bulk nature of the superconductivity and this paramagnetic to 


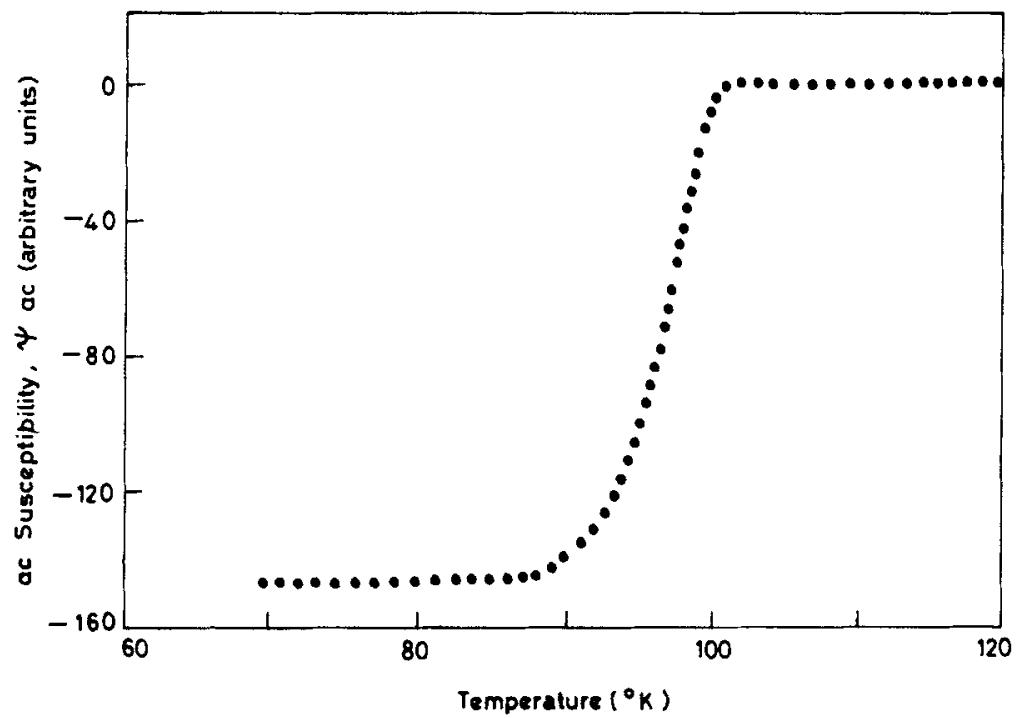

Figure 3. Temperature dependence of a.c. susceptibility of $\mathrm{Bi}_{2} \mathrm{Sr}_{2} \mathrm{Ca}_{1} \mathrm{Cu}_{2} \mathrm{O}_{8}$ sintered at $1138 \mathrm{~K}$ for $24 \mathrm{~h}$.

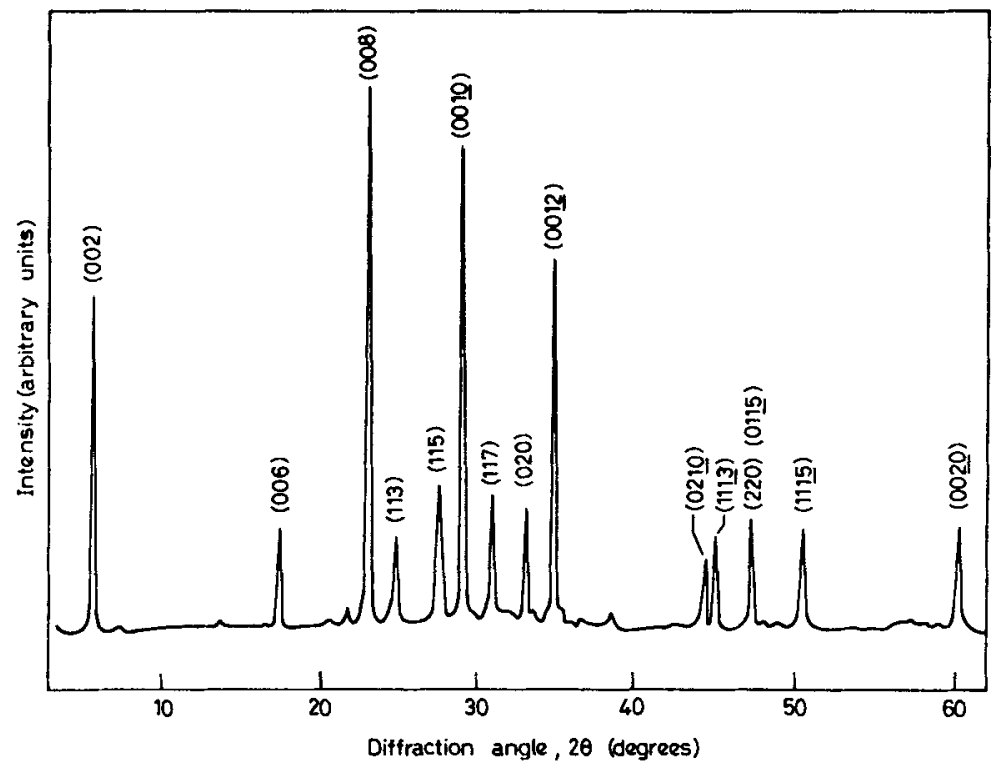

Figure 4. X-ray diffraction pattern at room temperature for $\mathrm{Bi}_{2} \mathrm{Sr}_{2} \mathrm{Ca}_{1} \mathrm{Cu}_{2} \mathrm{O}_{8}$ sintered at $1138 \mathrm{~K}$ for $24 \mathrm{~h}$.

diamagnetic transition may be related to the fact that the sample is single-phase and homogeneous.

The X-ray diffraction pattern of the sample is given in figure 4. The observed reflections were characteristic of a tetragonal structure with lattice parameters, $a=0.5398 \mathrm{~nm}$ and $c=3.0620 \mathrm{~nm}$, which are consistent with those previously reported (Almond et al 1988). No other phase is present. 
Table 1. Effect of annealing conditions on the superconductivity of $\mathrm{Bi}_{2} \mathrm{Sr}_{2} \mathrm{Ca}_{1} \mathrm{Cu}, \mathrm{O}_{8}$

\begin{tabular}{|c|c|c|c|c|}
\hline \multicolumn{3}{|c|}{ A inealing conditions } & \multicolumn{2}{|c|}{$T_{e}$} \\
\hline $\begin{array}{l}\text { Temperature } \\
(\mathrm{K})\end{array}$ & $\begin{array}{l}\text { Time } \\
\text { (h) }\end{array}$ & $\begin{array}{c}\mathrm{O}_{2} \text { pressure } \\
\text { (bar) }\end{array}$ & $\begin{array}{l}\text { Onset } \\
(K)\end{array}$ & $\begin{array}{c}\text { Offset } \\
(\mathrm{k}\rangle\end{array}$ \\
\hline 873 & 24 & 0.01 & 100 & 85 \\
\hline 873 & 24 & 0.1 & 98 & 83 \\
\hline 873 & 24 & 1.0 & 95 & 80 \\
\hline 873 & 24 & 10.0 & 90 & 75 \\
\hline 873 & 24 & 100.0 & 85 & 70 \\
\hline 873 & 12 & 0.01 & 100 & 85 \\
\hline 873 & 4 & 0.01 & 100 & 85 \\
\hline 973 & 24 & 0.01 & 100 & 85 \\
\hline 1073 & 24 & 0.01 & 100 & 85 \\
\hline
\end{tabular}

Sintered $\mathrm{Bi}_{2} \mathrm{Sr}_{2} \mathrm{Ca}_{1} \mathrm{Cu}_{2} \mathrm{O}_{8}$ samples were annealed in flowing oxygen at various pressures, temperatures and times. The sample resistivity decreases indicating the disappearance of intermediate phases formed, if any, during calcining and sintering which is also reflected in the XRD spectra taken on these samples. In addition, the zero resistivity temperature was reduced significantly depending on the oxygen partial pressure. The effect of annealing conditions on the superconducting properties of $\mathrm{Bi}_{2} \mathrm{Sr}_{2} \mathrm{Ca}_{1} \mathrm{Cu}_{2} \mathrm{O}_{8}$ is shown in table 1 . It is seen that with increasing treatment pressure and oxygen content, $T_{c}$ shifts progressively to a lower temperature. This may be due to the fact that the added oxygen ions lower the Fermi level thereby reducing the metallic conductivity of the $\mathrm{Bi}-\mathrm{O}$ layers and hence lowers $T_{\mathrm{c}}$ (Morris et at 1989). With increase in oxygen content, the transitions are broadened. With increase in annealing time beyond $4 \mathrm{~h}$, no systematic change in $T_{c}$ is found, indicating that the treatment time of $4 \mathrm{~h}$ is sufficient. Also, increasing the treatment temperature had little effect on zero resistivity temperature. However, increasing the treatment temperature from 873 to $973 \mathrm{~K}$ resulted in $25^{\circ}$ oreduction in a.c. susceptibility at $70 \mathrm{~K}$; and treatment at $1073 \mathrm{~K}$ caused about $50^{\circ}{ }_{0}$ reduction. It is therefore clear that if the samples are annealed in oxygen in a partial pressure of $\leqslant 0.01$ bar at $873 \mathrm{~K}$ for at least $4 \mathrm{~h}$ and then cooled slowly, it is possible to achieve the highest $T_{c}$ of $85 \mathrm{~K}$.

\section{Conclusions}

$\mathrm{Bi}_{2} \mathrm{Sr}_{2} \mathrm{Ca}_{1} \mathrm{Cu}_{2} \mathrm{O}_{8}$ ceramics, sintered at $1138 \mathrm{~K}$ for $24 \mathrm{~h}$ in air and slowly furnace-cooled to room temperature are single-phase, exhibit tetragonal structure with lattice parameters $a=0.5398 \mathrm{~nm}$ and $c=3.0620 \mathrm{~nm}$, and had the highest zero resistivity temperature of $88 \mathrm{~K}$. Resistivity and a.c. susceptibility measurements give similar values for the onset $(100 \mathrm{~K})$ of superconducting transition. The $T_{i}$ gets lowered with increased oxygen concentration.

\section{Acknowledgement}

The authors thank the University Grants Commission. New Delhi for financial assistance. 


\section{References}

Almond D P, Chapman B and Saunders G A 1988 Supercond. Sci. Technol. 1123

Gadkari S C, Muthe K P, Gupta S K, Singh K D, Sabharwal S C and Gupta M K 1988 Proc. of the Solid State Phys. Symp. C31 198

Hazen R M, Prewitt C T, Angel R J, Ross N L, Finger L W, Hadidiacos C G, Veblen D R, Heaney P J, Hor P H, Meng R L, Sun Y Y, Wang Y Q, Xue Y Y, Huang Z J, Gao L, Bechtold J and Chu C W 1988a Phys. Rev. Lett. 601174

Hazen R M, Finger L W, Angel R J, Prewitt C T, Ross N L, Hadidiacos C G, Heaney P J, Veblen D R, Shen Z Z, El Ali A and Hermann A 1988b Phys. Rev. Lett. 601657

Liu Zhi Yi and Persson M 1988 Supercond. Sci. Technol. 1198

Maeda H. Tanaka Y, Fukutomi M and Asano T 1988 Jpn J. Appl. Phys. 27 L.209

Morris D E, Hultgren C T, Markelz A M, Wei J Y T, Asmar N G and Nickel J H 1989 Phys. Rev. B39 6612

Perrin A, Li Z Z, Pena O, Pinel J, Padiou J and Sergent M 1988 Supercond. Sci. Technol. 1201

Syono Y, Hiraga K, Kobayashi N, Kikuchi M, Kusaba K, Kajitani T, Shindi D, Hasaya S, Tokiwa A, Terada S and Muto Y 1988 Jpn J. Appl. Phys. 27 L569

Takayama-Muromachi E, Uchida Y, Ono A, Izumi F, Onoda M, Matsui Y, Kosuda K, Takekawa S and Kato K 1988 Jpn J. Appl. Phys. 27 L365

Tallon J L, Buckley R G, Gilberd P W, Presland M R, Brown E W M, Bowden M E, Christian L A and Goguel R 1988 Nature (London) 333153

Tarascon J M, Le Page Y. Barboux P, Bagley B G, Greene L H, McKinnon W R, Hull G W, Giroud M and Hwang D M 1988 Phys. Rev. B37 9382

Torrance J B, Tokura Y, Laplaca S J, Huang T C, Savoy R J and Nazzal A I 1988 Solid State Commun. 66703

Zandbergen H W, Huang Y K, Menken M J V, Li J N, Kadowaki K, Menovsky A A, van Tendeloo G and Amelinckx S 1988 Nature (London) 332620 